\title{
Plant water use strategy determines winners and losers under climate change
}

\author{
Kristiina Visakorpi ${ }^{1}$, Sebastián Block ${ }^{2}$, Loïc Pellissier ${ }^{3}$, Jonathan Levine ${ }^{4}$, and Jake \\ Alexander ${ }^{5}$ \\ ${ }^{1}$ Norwegian University of Science and Technology \\ ${ }^{2}$ Princeton University \\ ${ }^{3}$ ETH Zurich \\ ${ }^{4}$ Princeton Environmental Institute \\ ${ }^{5}$ ETH Zürich
}

January 17, 2022

\begin{abstract}
Understanding the traits mediating species' responses to climate change is a cornerstone for predicting future community composition and ecosystem function. Although species' eco-physiological properties determine their response to environmental change, most trait-based studies focus on a small subset of easily-measured morphological traits as proxies for physiology. This choice may limit our ability to predict the impacts of climate change on species' demography, and obscure the underlying mechanisms. We conducted a transplantation experiment along a $1000 \mathrm{~m}$ Alpine elevation gradient to quantify the degree to which plant demographic responses to climate were predicted by eco-physiological performance versus common morphological traits. Although physiological measurements revealed that warming favored species with a conservative water use strategy, the predictive power of physiological traits did not exceed that of morphological traits. Our results show that while easily-measured morphological traits can successfully predict demographic responses to climate, eco-physiological approaches are needed to understand mechanism.
\end{abstract}

\section{Title: Plant water use strategy determines winners and losers under climate change}

Running title: Plant ecophysiology as predictor for demography

Kristiina Visakorpi ${ }^{1,2,}{ }^{*}$, Sebastián Block (munguia@princeton.edu) $)^{1,3}$, Loïc Pellissier (loic.pellissier@usys.ethz.ch) $)^{1,2}$, Jonathan M. Levine (levinej@princeton.edu) ${ }^{3}$ and Jake Alexander (jake.alexander@usys.ethz.ch) ${ }^{1}$

1) Department of Environmental Systems Science, ETH Zürich, Zürich, Switzerland

2) Swiss Federal Research Institute WSL, Birmensdorf, Switzerland

3) Department of Ecology and Evolutionary Biology, Princeton University, Princeton, New Jersey, USA

* Corresponding author

Address: ETH Zürich CHN, H12.1, Universitätstrasse 16, 8006 Zürich, Switzerland

Phone: +447468887679

Email: kristiina.visakorpi@gmail.com

Type of article: Letter 
148 words in the abstract, 4980 words in the main text, 82 references, 4 figures and 2 tables.

Keywords: plant, ecophysiology, functional, traits, climate change, alpine

Statement of authorship: SB, LP, JL and JA designed and set up the experiment, SB and KV collected the data, KV analyzed the data and wrote the first version of the manuscript, and all authors contributed substantially to revisions.

Data availability statement: Should the manuscript be accepted, the data supporting the results will be archived in Figshare.

\begin{abstract}
Understanding the traits mediating species' responses to climate change is a cornerstone for predicting future community composition and ecosystem function. Although species' eco-physiological properties determine their response to environmental change, most trait-based studies focus on a small subset of easily-measured morphological traits as proxies for physiology. This choice may limit our ability to predict the impacts of climate change on species' demography, and obscure the underlying mechanisms. We conducted a transplantation experiment along a $1000 \mathrm{~m}$ Alpine elevation gradient to quantify the degree to which plant demographic responses to climate were predicted by eco-physiological performance versus common morphological traits. Although physiological measurements revealed that warming favored species with a conservative water use strategy, the predictive power of physiological traits did not exceed that of morphological traits. Our results show that while easily-measured morphological traits can successfully predict demographic responses to climate, eco-physiological approaches are needed to understand mechanism.
\end{abstract}

\title{
Introduction
}

Climate is changing faster now than it has in the last 2000 years (IPCC 2021), and ecological communities are being reshuffled as a consequence (Davis \& Shaw 2001; Parmesan \& Yohe 2003). Predicting which types of species are likely to suffer or benefit from changing climate and interaction networks is needed for accurate estimates of future community composition and ecosystem function.

How plant species respond to environmental change depends on their eco-physiological properties (Beyschlag \& Ryel 2007; Taiz \& Zeiger 2010). Knowledge of species' physiology can improve predictions of mortality (Anderegg et al. 2016), species' distributions (Borchert 1994; Kearney \& Porter 2009) and ecosystem-level processes (Verheijen et al. 2013; Fyllas et al. 2014). Nevertheless, as plant eco-physiological traits can be time-consuming to measure and thus often absent from trait databases, they are rarely used to predict changes in plant community composition. Instead, most studies predicting climate change responses in plant communities rely on morphological traits (e.g. leaf mass per area, height), which are assumed to indirectly describe species physiology and resource acquisition (Lavorel \& Garnier 2002; Shipley et al. 2016).

Functional trait based-approaches have had varying success in identifying "winning" or "losing" traits under environmental change. For example, warming benefits alpine plants with thick leaves and high leaf mass per area (Soudzilovskaia et al. 2013) and tall Arctic species (Bjorkman et al. 2018). Nevertheless, many studies using the same set of traits have shown them to be poor predictors of population dynamics (Paine et al. 2015; Yang et al. 2018; Swenson et al. 2020) or ecosystem properties (van der Plaset al. 2020). This has raised the question whether successful trait-based predictions of environmental responses are the exception rather than the rule (Yang et al. 2018). It remains unclear whether failures of traits to predict population trends reflect the limitations of the traits commonly measured, or limitations of the trait-based approach more generally.

The focus on easily-measured morphological traits has three potential problems. First, the narrow selection of traits is likely to miss important functional dimensions (e.g. belowground or night-time processes; Yang et al. 2018; Medeiros et al. 2019). Second, traits are often measured under fixed environmental conditions (Yang et al. 2018). Yet, trait plasticity can be an important predictor of demographic change, either as an indicator of species' ability to acclimate to new environmental conditions (Siefert et al. 2015; Zhang et al. 2020), or species' 
ability to rapidly respond to a change in the environment (Volaire et al. 2020). Third, the indirect nature of the commonly measured morphological traits hides the mechanism underlying the relationship between a given trait value and the response of interest (Rosado et al. 2013; Brodribb 2017). For example, one of the most frequently measured traits, leaf mass per area, can be used to describe photosynthetic capacity, herbivory tolerance, water economy, cold-hardiness and competitive ability (Westoby 1998; Vendramini et al. 2002; Poorter et al. 2009). Ultimately, not knowing the mechanism behind plant response to the environment makes it challenging to predict ecosystem-scale responses to environmental perturbations (Smith et al. 2009; Griffin-Nolan et al. 2018).

In addition to the shortcomings caused by the narrow selection of traits, the role of biotic interactions in determining the "winning" traits is rarely disentangled from the role of the abiotic environment. This is true despite the fact that these two aspects of the environment are changing in parallel (Suttle et al. 2007; Vandvik et al. 2020) and are likely to favor different trait combinations (e.g. stress tolerance vs competitive ability, De Bello et al. 2005; Grime 2006). Thus, using traits as predictors of species' response to changing climate might be unsuccessful if the role of biotic interactions in shaping the successful trait combination is not considered.

We leveraged a transplant experiment along a $1000 \mathrm{~m}$ elevation gradient in the Swiss Alps to explore how plant morphological and eco-physiological traits predict species' demographic responses to climate warming and changing competitive interactions. We measured the demographic responses and traits of alpine species transplanted to lower elevations to simulate climate warming, to answer the following questions:

1. Do traits measured under current alpine conditions predict differences in how species respond to warmer climate? Alternatively, is the plastic response to warming more predictive of the demographic response?

2. Do eco-physiological traits perform better than morphological traits as predictors of demographic responses to climate warming?

3. Do the traits associated with greater performance under warming differ from those associated with persistence with novel competitors?

We expected the following: (1) Given that resource-acquisitive traits can be detrimental when resources are limiting, and advantageous when not, (Fridley et al. 2016; Zhang et al. 2020), species with resourceacquisitive traits should be most responsive to the manipulations (either suffering e.g. due to water shortage or benefiting e.g. from a longer growing season). (2) As the ability to acclimate can be important for survival in changing environments (Ripley et al.2020; Zhang et al. 2020), species with greater trait plasticity should perform better with warming. (3) Assuming physiological measurements better indicate plant resource acquisition than do indirect morphological traits (Rosado et al. 2013), eco-physiological traits should be the better predictors of species' demographic response to the manipulations. (4) Finally, as theory predicts that plant strategies for tolerating abiotic vs biotic stress trade-off with one another (Grime 2006), different sets of traits should be beneficial in dealing with warming vs. novel competitors. We found that traits related to size and conservative water use when measured under current climate were most predictive of species' demographic response to the climate manipulation. Our results show that both morphological and eco-physiological traits can be used for predictions, but with different interpretation of the underlying mechanism.

Materials and methods

\section{Experimental setup}

The experiment was conducted in the eastern Swiss Alps (Calanda mountain, 46deg88'N, 9deg49'E). In October 2016, $1 \mathrm{~m}$ x $1 \mathrm{~m}$ turfs of alpine vegetation were transplanted from $2050 \mathrm{~m}$ to a nearby site at $2000 \mathrm{~m}$ (hereafter " $+0 \operatorname{deg} C$ "), and to three lower elevations with ten replicate turfs at each site. The three lower elevations created a gradient of warming temperatures: $1600 \mathrm{~m}("+2 \mathrm{deg} C$ ", the adiabatic rate of temperature), $1400 \mathrm{~m}$ ("+3degC") and $1000 \mathrm{~m}$ ("+5degC"). The sites were also situated along a gradient of decreasing average soil moisture, from $34.3 \%$ at $2000 \mathrm{~m}$ to $22.6 \%$ at $1000 \mathrm{~m}$. The changes in precipitation and temperature along the gradient were consistent with climate change predictions for the region (Appenzeller 
\& Center for Climate Systems Modeling 2011). An additional ten turfs were transplanted to the $1400 \mathrm{~m}$ site, and planted with individuals of 12 lowland species. This treatment mimicked the establishment of novel low-elevation competitors in an alpine community under warmer climate.

We measured the demographic response to climate change by surveying the abundance of each alpine species in the turfs near the peak of the growing season at each site from 2017 to 2020. Weather stations recorded air and soil temperature, air relative humidity and soil moisture from May to October in 2019 and 2020 (Table 1, Figure S1). Further details of all methods are presented in the "Detailed methods" section of Supporting Information.

\section{Trait measurements}

We measured 27 traits (Table 2) which together describe plant morphology, leaf structure, plant gas exchange and its temperature dependence, and plant water use strategy. For the thirteen of these traits which we measured at more than one elevation, we calculated plasticity indices. We made these trait measurements on 16 target species (Table S1), chosen to represent several plant families, to be widely present in the turfs in most treatments, and to have leaves which fitted into the gas analyzer.

Traits describing plant morphology and leaf structure were measured at the source elevation $(2000 \mathrm{~m})$ in August 2019 and 2020. To measure leaf area (LA), leaf mass per area (LMA), leaf thickness (LT), and leaf dry matter content (LDMC), we collected leaves of the target species, scanned them and measured their fresh and oven-dried weight. LT was measured with calipers from the fresh leaves. LA was estimated from the leaf scans with the software ImageJ (Rasband 1997). Canopy shape index (CSI) was measured as the ratio of mean canopy width to height (ranging from near zero for tall plants to $>1$ for prostrate plants). Rooting depth $\left(\right.$ Root $\left._{\mathrm{d}}\right)$ and width $\left(\operatorname{Root}_{\mathrm{w}}\right)$ were measured from excavated root systems.

To characterize plant gas exchange, we measured photosynthesis (A), nighttime respiration (R), stomatal conductance during day and night $\left(\mathrm{GS}, \mathrm{GS}_{\text {night }}\right)$, transpiration during day and night $\left(\mathrm{E}, \mathrm{E}_{\text {night; }}\right.$ for the importance of night-time water flux, see Snyder 2003; Daley \& Phillips 2006), instantaneous water use efficiency $\left(\mathrm{WUE}_{\text {inst }}\right)$ and intrinsic water use efficiency $\left(\mathrm{WUE}_{\text {int }}\right.$ ) with an infra-red gas analyser (CIRAS-2, PPSystems, Hitchin, UK). To quantify how photosynthesis or respiration varied after transplantation to lower elevation, measurements were taken from two sites: $+3 \operatorname{degC}(1400 \mathrm{~m})$ and $+0 \operatorname{degC}(2000 \mathrm{~m})$. Temperature in the leaf chamber was kept constant at either $24 \mathrm{degC}$ (day measurements) or $14 \mathrm{degC}$ (night measurements). Gas exchange measurements were taken in 2019 and 2020, 3-4 years after the transplantation.

To characterize the instantaneous response of gas exchange to temperature, we measured photosynthesis and respiration response to temperature at $2000 \mathrm{~m}(+0 \mathrm{degC})$ using both a CIRAS-2 and Licor-6800 (LICOR, Lincoln, Nebraska, USA). Photosynthesis was measured at $14 \mathrm{deg} \mathrm{C}-34 \mathrm{deg}$, at $4 \mathrm{degC}$ intervals, and respiration at $5 \operatorname{deg} \mathrm{C}-30 \operatorname{deg} \mathrm{C}$, at $5 \operatorname{deg} \mathrm{C}$ intervals. After, the leaves were scanned, oven-dried, weighted and milled to measure carbon $(\mathrm{C})$ and nitrogen $(\mathrm{N})$ content either with combustion analysis (for large samples) or with an elemental analyzer coupled to a mass spectrometer (for small samples, Werner et al. 1999; Werner \& Brand 2001). Leaf scans and weights were used to estimate change in LMA and LA resulting from transplantation. Photosynthetic nitrogen use efficiency (PNUE) was calculated by dividing mass-based photosynthetic rate (A/LMA) with the $\mathrm{N}$ content of the same leaf.

Plant water use strategy was characterized by measuring stable isotope ratios in ${ }^{13} \mathrm{C} /{ }^{12} \mathrm{C}$ and ${ }^{18} \mathrm{O} /{ }^{16} \mathrm{O}$ (to determine long-term stomatal conductance and water use efficiency $\left(\delta^{13} \mathrm{C}\right.$ and $\delta^{18} \mathrm{O}$; Scheidegger et al. 2000; Moreno-Gutiérrez et al. 2012). $\delta^{13} \mathrm{C}$ is a proxy for intrinsic water use efficiency (A/GS) and $\delta^{18} \mathrm{O}$ correlates negatively with stomatal conductance (GS), both integrated over the leaf life span. Leaf samples collected at each site were oven-dried and cut into small pieces for cellulose extraction. Measurements of $\delta^{13} \mathrm{C}$ and $\delta^{18} \mathrm{O}$ from the extracted cellulose were performed using a PYROCUBE (Elementar, Hanau, Germany) connected to a Delta Plus XP mass spectrometer (Thermo Finnigann, Bremen, Germany) at the laboratory of stable isotopes at the Swiss Federal Institute of Forest, Snow and Landscape (WSL), following Weigt et al. (2015).

We measured the depth of water uptake by comparing the $\delta^{18} \mathrm{O}$ of root crown water to the $\delta^{18} \mathrm{O}$ of water from 
different soil depths (Barnard et al. 2006; Moreno-Gutiérrez et al. 2012). Root crowns were collected into airtight vials and pooled together per species and site to ensure enough water per sample. Soil was collected from each site with soil corers (max $35 \mathrm{~cm}$ depth) and separated every $5 \mathrm{~cm}$ into airtight glass vials. Water was extracted from samples in the lab by using a water bath and cooling traps. $\delta^{18} \mathrm{O}$ was analysed from the extracted water with a High Temperature Combustion Elemental Analyzer (TC/EA; Thermo Finnigan, Bremen, Germany) and a mass spectrometer (Delta plus XP; Thermo Finnigan) (Saurer et al. 2016). Since each site was sampled on only one occasion (and the measurements could be influenced by weather), we used the average depth across all four sites as the species-level trait in the analyses. As source water $\delta^{18} \mathrm{O}$ can drive variation in leaf cellulose $\delta^{18} \mathrm{O}$ (Roden \& Farquhar 2012), we used $\delta^{18} \mathrm{O}$ enrichment $\left(\delta^{18} \mathrm{O}\right.$ leaf cellulose $-\delta^{18} \mathrm{O}$ root crown water) as the estimate of long-term stomatal conductance (Scheidegger et al. 2000; Moreno-Gutiérrezet al. 2012). See Supporting Information Table S2 for sample sizes for all traits.

\section{Data processing}

To extract parameters from the photosynthesis-temperature response curves (Figure S2), we fitted an equation after June et al.(2004), yielding two parameters: optimal temperature for photosynthesis $\left(\mathrm{T}_{\mathrm{Opt}}\right)$ and the temperature range for photosynthesis $\left(\Omega \cdot\right.$ at which photosynthesis falls to $\mathrm{e}^{-1}$ of its value at $\mathrm{T}_{\mathrm{opt}}$, Eq. S1). To estimate respiration sensitivity to temperature (Figure S3), we fitted an exponential equation, estimating the change in respiration rate with a temperature increase of $10^{\circ} \mathrm{C}$ (" $\mathrm{Q}_{10}$, Eq. S2-S3, Tjoelker et al. 2001; Atkinet al. 2005).

We calculated a measure of plasticity for all the traits that had been collected from more than one site (Table 2). For traits measured at all the four sites we calculated a simplified relative distance plasticity index ("RDPIS") after Valladares et al. (2006). The index ranges from 0 (no plasticity) to 1 (maximal plasticity) and is calculated as the sum of absolute trait differences divided by the sum of the traits (Eq. S4), and is recommended for ranking species according to their plasticity (Valladares et al. 2006). For traits that were measured in only two treatments, we used the same approach (i.e. (mean at lower elevation - mean at origin) / sum), but with a signed (+/-) rather than absolute value of the trait differences, so that we could measure the direction of change between the two sites (Eq. S5).

\section{Statistical analyses}

\section{Demographic response to transplantation explained by traits}

To investigate if traits explained demographic responses to transplantation, we quantified species' position in multivariate trait space by performing a Principal Component Analysis ("PCA"). We included all 27 traits measured at $2000 \mathrm{~m}\left(\right.$ " $+0^{\circ} \mathrm{C}$ ") and six plasticity indices for those traits that showed significant differences between sites on average ( $\mathrm{WUE}_{\text {inst }}$, GS $\mathrm{Sight}_{\text {night }}, \mathrm{E}_{\text {nigh }} \delta^{18} \mathrm{O}$ enrich, $\delta^{13} \mathrm{C}$ and depth, Figures S4-S7). To test if species' locations in the trait space related to their demographic responses to transplantation to lower elevation, we built linear mixed effects models (LMMs) with either 2020 cover $\left(\mathrm{cm}^{2}\right)$ or frequency (number of quadrants where species was present) as the response variable. We used both species cover and frequency, because we expected these to correspond to different demographic processes: while changes in frequency depend on species' survival and recruitment, changes in cover are also influenced by vegetative growth (and, in contrast to frequency, potentially by errors in cover estimations). The response was modeled as a function of the initial cover or frequency of the species per site in 2017, the mean summer temperature at each site, the first four PC trait axes and the two-way interactions between the trait axes and temperature. The significance of fixed effects was assessed by dropping one explanatory variable at a time, starting from a full model. The change in the model fit was assessed using likelihood ratio tests (Crawley 2007). For responses showing a significant trait axis $\times$ treatment interaction, we evaluated the amount of variation explained by calculating pseudo- $\mathrm{R}^{2}$ (Nakagawa \& Schielzeth 2013). To estimate the usefulness of traits as predictors, we compared the amount of variation explained by traits to that explained by species identity. To do so, we compared variation explained by models with or without species or traits as fixed effects (see Table S3 for details).

To further investigate which traits were associated with demographic response to climate, we tested if 
warming resulted in communities of species possessing particular trait values. We calculated communityweighted means for each trait per each replicate turf across the four sites, based on the 2020 percent cover of all species and their $2000 \mathrm{~m}\left(+0^{\circ} \mathrm{C}\right)$ trait value. The only exceptions were $\delta^{18} \mathrm{O}$ and $\delta^{13} \mathrm{C}$, for which we used both the site-specific trait values, and the values as measured at $2000 \mathrm{~m}\left(+0^{\circ} \mathrm{C}\right)$. For these two traits, we evaluated the degree to which changes in community-weighted trait means were due to within-species trait change versus species turnover. Differences in community-weighted mean trait values between sites were tested with linear models.

\section{Comparing morphological vs eco-physiological traits}

To compare the importance of morphological vs eco-physiological traits in explaining species' demographic responses, we performed two additional PCAs: one with only morphological/leaf structural traits (height, width, $\operatorname{Root}_{\mathrm{d}}$, Root ${ }_{\mathrm{w}}$, CSI, LMA, LA, LT, LDMC, C, N and C:N), and another with only eco-physiological traits (defined as describing internal chemical or physical processes and their responses to the environment: A, E, GS, WUE $E_{\text {intr }}, W_{E_{\text {inst }}}$, PNUE, R, GS night $, \mathrm{E}_{\text {night }}, \delta^{13} \mathrm{C}, \delta^{18} \mathrm{O}$, depth, $\mathrm{T}_{\text {opt }}, \Omega$ and $\left.\mathrm{Q}_{10}\right)$. We then built LMMs as described above with the two first axes of both PCA's to evaluate their ability to predict demographic change.

To investigate if morphological traits could be used as proxies of physiology, we first calculated correlation coefficients for each physiological-morphological trait pair. We then tested if the whole morphological trait space correlated with the eco-physiological trait space by performing a co-inertia analysis between the two PCAs (Drayet al. 2003). The significance was tested with a permutation test $(\mathrm{n}=99)$. Finally, we evaluated how predictions of species' vulnerability to climate warming would differ if we based the predictions on either morphological or eco-physiological traits only. To this end, we ranked species from least to most vulnerable to warming based on their locations on the trait axes.

\section{Effect of novel competitors}

We tested if species' demographic response to novel competitors depended on their trait values. We built a LMM of the species' cover or frequency in 2020 as a function of the cover/frequency in 2017, competitor treatment (alpine vs novel), the four trait axes of the PCA including all traits, and the two-way interactions between competitor treatment and the trait axes.

Species identity was a random effect in all LMMs. Model assumptions were validated by examining plots of residuals against fitted values for the homoscedasticity of residuals, and a Quantile-Quantile plot for the normal distribution of the residuals. Analyses were conducted in the R version 3.6.2 (R Core Team 2018).

Results

\section{Demographic response to transplantation explained by traits}

Six species decreased, and five species increased in cover in the warmer sites compared to the origin. Five decreased in frequency but increased or showed no change in cover (Table S1, Figures S8-S9). Of the full trait space, the first four axes explained $63 \%$ of the variation $(21 \%, 15 \%, 15 \%$ and $12 \%)$. The first axis separated species based on their water use efficiency measured with the gas-analyser $\left(\mathrm{WUE}_{\text {inst }}\right.$, WUE $\mathrm{W}_{\text {int }}$, E). The second axis separated species with high values of $\delta^{13} \mathrm{C}$ and $\delta^{18} \mathrm{O}$ enrichment (i.e. "conservative" water use strategy) and large size (width, leaf area) from small species with "prolific" water use strategy. The third axis separated species which increased their $\mathrm{WUE}_{\text {inst }}$ after transplanting (high $\mathrm{WUE}_{\text {inst }}$.PI), had a high sensitivity of respiration to temperature (high $\mathrm{Q}_{10}$ ) and low leaf nitrogen content from species with opposite traits. The fourth axis separated species with prostate growth form (high CSI), high stomatal conductance, high nighttime transpiration and low temperature optima for photosynthesis from tall, erect and deep-rooted species with opposite physiological traits (Figure S10).

A species' position on the second trait axis correlated with its demographic response to increasing temperature both when measured as cover $\left(\chi^{2}(1)=5.69, \mathrm{p}=0.017\right.$, Figure S11a) and frequency $\left(\chi^{2}(1)=14.5, \mathrm{p}<\right.$ 0.001 ; interaction axis $2 \times$ temperature, Figure 1a, Tables S4-S5). Small species in terms of width and leaf 
area with high life-time stomatal conductance (low $\delta^{18} \mathrm{O}$ ) and low water use efficiency $\left(\right.$ low $\delta^{13} \mathrm{C}$; "prolific" water use strategy) declined in cover and frequency at the warmer relative to cooler sites. Additionally, a species' position on the first PCA axis correlated with its frequency change: species with high $\mathrm{WUE}_{\text {inst }}$ and WUE $_{\text {int }}$ and low E reduced in frequency more than species with opposite traits at all sites $\left(\chi^{2}(1)=5.55, \mathrm{p}=\right.$ 0.019; Figure S11b). A species' position on the two other trait axes did not correlate with their demographic response to warming (Table S5). The best LMMs derived from model selection (including initial cover or frequency, temperature and its interactions with traits, and species identity) explained $59 \%$ of the variation in cover and $69 \%$ in frequency, of which species identity explained $25 \%$ and $12 \%$, and traits explained $10 \%$ and $12 \%$ (Table S3).

At the community-level, turfs transplanted to lower elevations were more likely to contain larger species (height and width; $(\mathrm{F}(1,48)=4.88, \mathrm{p}=0.03 ; \mathrm{F}(1,48)=15.08, \mathrm{p}<0.001)$ with a conservative water use strategy (high $\delta^{13} \mathrm{C}$ and $\delta^{18} \mathrm{O} ; \mathrm{F}(1,48)=68.57, \mathrm{p}<0.001 ; \mathrm{F}(1,48)=4.54, \mathrm{p}=0.04$; Figure 3, Figure S12bc and Table S6).

Several traits $\left(W E_{\text {ins, }}\right.$ gs night $, E_{\text {night }}, \delta^{18} \mathrm{O}, \delta^{13} \mathrm{C}$ ) showed plasticity, and the direction of the change differed between species (Figures S4-S7, S13). Notably, photosynthesis and respiration were on average similar when measured at $+0^{\circ} \mathrm{C}$ and $+3^{\circ} \mathrm{C}$ (i.e. there was no clear evidence of acclimation, Figure S4a,f). None of the plasticity indices nor the parameters describing species' ability to rapidly adjust to temperature $\left(\mathrm{T}_{\mathrm{opt}}, \Omega\right.$, $\mathrm{Q}_{10}$ ) were important predictors of the demographic changes. Even though transplantation to lower elevations favored species with conservative water use, it resulted in higher life-time stomatal conductance and lower water use efficiency (low $\delta^{18} \mathrm{O}$ enrichment and $\delta^{13} \mathrm{C}$ ) within species (Figures S5-S6).

\section{Comparing morphological vs ecophysiological traits}

The PCA constructed only from morphological traits separated species according to leaf structure (PC1: C, N, C:N, LDMC, LT) and plant size (PC2: width, height, LA, Root.w, Figure 2a,c). The PCA with only ecophysiological traits separated species based mainly on their gas exchange (PC1: E, WUE $\mathrm{intr}_{\text {r }}, \mathrm{WUE}_{\text {inst }}$, GS, R) and water use strategy $\left(\mathrm{PC} 2: \delta^{13} \mathrm{C}, \delta^{18} \mathrm{O}\right.$, GS, depth, Figure $\left.2 \mathrm{~b}, \mathrm{~d}\right)$. The second axes of both PCAs (i.e. describing size/ water use strategy) correlated with species' frequency response to transplantation $\left(\chi^{2}(1)=12.3, \mathrm{p}<0.001\right.$ and $\left.\chi^{2}(1)=9.1, \mathrm{p}=0.003\right)$ and did so as described above for the full trait PCA (i.e. small species with prolific water use decreasing at warmer sites; Figure 1b,c). The second axis of the ecophysiological PCA describing water use strategy $\left(\chi^{2}(1)=4.54, \mathrm{p}=0.03\right)$ also predicted species cover change but it was the first axis of the morphological PCA describing leaf structural traits that was associated with cover change $\left(\chi^{2}(1)=7.81, p=0.005\right.$; species with thick, nitrogen-rich leaves reducing in cover, Figure $\mathrm{S} 11 \mathrm{c}, \mathrm{d})$. The amount of variation in the cover or frequency response explained by the LMMs did not depend on whether all traits, only morphological traits, or only ecophysiological traits were included (Table S3).

The two PCAs correlated significantly with each other $(\mathrm{RV}=0.37, \mathrm{p}=0.01$, Figure S14), even though most of the pairwise correlations between morphological and ecophysiological traits were non-significant (Figure S15). Using only size-related morphological traits or only ecophysiological traits resulted in a similar ranking of the winning and losing species (Figure 4), whereas the ranking based on leaf structural traits was different (Table S7).

\section{Effect of novel competitors}

The addition of novel competitors did not significantly affect the abundance of the alpine species, and none of the four trait axes of the full PCA correlated with species' demographic response to the treatment (Figures S16-S17, Table S5).

\section{Discussion}

As climate warming continues (IPCC 2021), predicting which species will "win" or "lose" is crucial for community- and ecosystem-level predictions. Here, we measured the abundance change of 16 alpine plant species as a response to climate warming in a manipulative field experiment, and related these responses to species traits. We found that species' demographic responses to the manipulation could be predicted 
by their size and water use strategy: small species with a more prolific water use suffered most from the transplantation to warmer and drier climates. Climate change is likely to influence water availability in the Alps by increasing the frequency and severity of heatwaves (Beniston 2004). Consequently, water limitation is likely to become an important driver of community change in alpine grasslands.

The advantage of traits related to conservative water use in a warming climate has been shown before: morphological traits describing conservative water use were related to increased abundance after warming in mountain plant communities (Soudzilovskaia et al. 2013), and drier conditions are likely to promote resource-conservative species in the Arctic (Bjorkman et al. 2018) and in the Mediterranean (Pérez-Ramos et al. 2012). Soil drying can be an important driver of plant community dynamics in other alpine and Arctic systems (Harte \& Shaw 1995; Chapin III et al. 1996). In our experiment, the largest change in species abundance occurred after a drought in 2018 that was particularly pronounced at the warmest site (Figure S18). Increased frequency of these types of extreme events could be critical for future plant community structure in the Alps (Jentsch \& Beierkuhnlein 2008; Liu et al. 2015).

Consistent with our assertion that climate change poses more of a water than a temperature challenge in our study system, we did not observe a shift towards species with higher thermal optima (i.e. higher $\mathrm{T}_{\text {opt }}$ and lower $\mathrm{Q}_{10}$ ). Such a shift would be expected if changes in community composition were driven by physiological adaptations to temperature per se. Previous studies have recorded "thermophilization" of alpine and Arctic plant communities due to climate warming, i.e. a shift towards "warm-adapted" species, as inferred from their distribution (Gottfriedet al. 2012; Govaert et al. 2021; Lynn et al.2021). Nevertheless, the distributional limit of a species might not reflect adaptation to temperature as such, but rather to correlated factors, such as soil moisture or competition. For example, competitive ability is likely to trade-off with cold tolerance (Koehler et al. 2012; Pellissier et al. 2018), allowing species without specific cold-adaptations to persist with higher levels of competition. In general, higher temperatures are rarely detrimental for alpine or arctic plants (Chapin 1983; Gauslaa 1984) and optimal temperatures for plant gas exchange change only a little across temperature gradients (Körner \& Diemer 1987).

Predicting the winners and losers in our experiment was possible by measuring either eco-physiological (longterm water use efficiency and stomatal conductance) or size-related morphological traits, and could have been possible with relatively few easily-measured traits (e.g. width and leaf area). Even though the individual morphological traits did not correlate with physiological processes, the whole morphological trait space correlated with the physiological trait space. Consequently, using size-related morphological traits resulted in a similar estimate of winning and losing species than using the full trait data set or eco-physiological traits only (Figure 4). Nevertheless, the interpretation of the mechanism behind species either "winning" or "losing" would be different depending on which traits are used for the predictions: a correlation with size-related traits would not reveal the role of water use strategy and decreasing soil moisture as potential drivers of community change.

Traits explained $10 \%$ of the variation in cover and $12 \%$ of the variation in frequency, less than for example $40 \%$ in Wright et al. (2010) (but more than e.g., $3 \%$ in Paine et al. 2015). Nevertheless, we think the variation explained by traits should be compared to that explained by species identity ( $25 \%$ and $12 \%$, respectively). In our experiment, plant cover and frequency were likely changing due to several factors which did not relate to differences between species, and thus could not be captured by trait measurements (e.g., chance events, microclimate). Our trait measurements captured almost half (40\%, Table S3) of the species-specific variation in cover change and all the variation in species-specific frequency change. Thus, in our study, traits were able to effectively capture the species-level differences in demographic rates, although better for one metric (frequency) than for the other (cover).

We observed within-species changes in most of the traits measured at multiple elevations, with the exact responses differing between species and traits. Contrary to previous studies (Pérez-Ramos et al.2019; Zhang et al. 2020) and to our expectations, trait plasticity was not important in explaining demographic change (but see Block et al. 2020). A potential explanation is that the magnitude of plastic responses to (even severe) climate change is small compared to trait difference between species (Aerts et al. 2007; Soudzilovskaia et al. 
2013, Table S8). Our results highlight that, despite the potential importance of plasticity, species-level trait values can be useful for demographic predictions (Albert et al. 2011; Kichenin et al. 2013).

Although communities shifted towards species with more conservative water use under warming, the plastic response showed the opposite pattern: at warmer, lower -elevation sites, individual species showed lower $\delta^{18} \mathrm{O}$ (higher stomatal conductance) and lower $\delta^{13} \mathrm{C}$ (lower water use efficiency). These trends likely follow from the increasing atmospheric pressure and temperature with decreasing altitude (Körner et al. 1991). Higher $\mathrm{CO}_{2}$ partial pressure resulting in more constrained $\mathrm{CO}_{2}$ diffusion through stomata (Smith \& Donahue 1991; Terashima et al. 1995; Wang et al. 2017), higher oxygen partial pressure resulting in lower carboxylation efficiency of Rubisco (Farquhar \& Wong 1984), and higher temperature resulting in decreased viscosity of water and faster transport from roots to leaves (Roderick \& Berry 2001), should all result in lower $\delta^{18} \mathrm{O}$ and $\delta^{13} \mathrm{C}$ values within species at lower elevations (Körneret al. 1988, 1991). This elevation-related shift to more inefficient water use might have resulted in a larger decrease in abundance in our experiment than would have taken place due to warming alone. Nevertheless, we think the mechanism identified (decreased water availability due to warming and the importance of water use traits) holds, even if the demographic effects of the water limitation might have been overestimated.

Contrary to our predictions, traits did not explain demographic changes caused by novel competitors. This is likely because the treatment had a relatively small influence on the resident community (Figures S16-S17). The treatment was set up to mimic the initial establishment of low-elevation species into alpine communities, and the four years of the experiment were likely not enough for them to significantly affect the alpine species.

\section{Conclusions}

In our study, drier conditions at lower elevations drove the demographic responses of alpine plants. Thus, alpine species with large size and conservative water use were more likely to benefit from the climate change. Both morphological and eco-physiological traits were successful in separating the "winners" of climate change from the "losers". Our study shows that while easy-to-measure morphological traits can generate successful predictions of demographic responses to climate, eco-physiological knowledge allows us to understand the mechanism behind the trait-environment relationships.

\section{Acknowledgements}

We thank Annika Ackermann and the Grassland Sciences group at ETH Zürich for the help with the CN -analyses, Matthias Saurer and Loïc Schneider at WSL for the help with the isotope analyses, Saran Karadaghi, Marc-Jacques Mächler, Sandra Racine, Evelin Iseli and and Annette Bieger Altermatt for the help in the field and the lab, and the Genetic Diversity Center at ETH for the use of laboratory facilities. This research was funded by ETH Zurich and the Swiss National Science Foundation grant 31003A_173210. JMA received funding from the European Union's Horizon 2020 research and innovation programme under grant agreement no. 678841 .

\section{References}

Aerts, R., Cornelissen, J.H.C., van Logtestijn, R.S.P. \& Callaghan, T.V. (2007). Climate change has only a minor impact on nutrient resorption parameters in a high-latitude peatland. Oecologia , 151, 132-139.

Albert, C.H., Grassein, F., Schurr, F.M., Vieilledent, G. \& Violle, C. (2011). When and how should intraspecific variability be considered in trait-based plant ecology? Perspectives in Plant Ecology, Evolution and Systematics , 13, 217-225.

Anderegg, W.R.L., Klein, T., Bartlett, M., Sack, L., Pellegrini, A.F.A., Choat, B., et al. (2016). Meta-analysis reveals that hydraulic traits explain cross-species patterns of drought-induced tree mortality across the globe. Proc Natl Acad Sci USA, 113, 5024-5029.

Appenzeller, C. \& Center for Climate Systems Modeling. (2011).Swiss climate change scenarios CH2011 . C2SM, Zürich. 
Atkin, O.K., Bruhn, D. \& Tjoelker, M.G. (2005). Response of plant respiration to changes in temperature: mechanisms and consequences of variations in Q10 values and acclimation. In: Plant Respiration: From Cell to Ecosystem (eds. Lambers, H. \& Ribas-Carbo, M.). Springer Netherlands, Dordrecht, pp. 95-135.

Barnard, R.L., de Bello, F., Gilgen, A.K. \& Buchmann, N. (2006). The $\delta 180$ of root crown water best reflects source water $\delta 18 \mathrm{O}$ in different types of herbaceous species. Rapid Commun. Mass Spectrom. , 20, 3799-3802.

Beniston, M. (2004). The 2003 heat wave in Europe: A shape of things to come? An analysis based on Swiss climatological data and model simulations. Geophys. Res. Lett. , 31.

Beyschlag, W. \& Ryel, R.J. (2007). Plant physiological ecology: An essential link for integrating across disciplines and scales in plant ecology. Flora - Morphology, Distribution, Functional Ecology of Plants , 202, 608-623.

Bjorkman, A.D., Myers-Smith, I.H., Elmendorf, S.C., Normand, S., Rüger, N., Beck, P.S.A., et al. (2018). Plant functional trait change across a warming tundra biome. Nature, 562, 57-62.

Block, S., Alexander, J.M. \& Levine, J.M. (2020). Phenological plasticity is a poor predictor of subalpine plant population performance following experimental climate change. Oikos , 129, 184-193.

Borchert, R. (1994). Soil and stem water storage determine phenology and distribution of tropical dry forest trees. Ecology , 75, 1437-1449.

Brodribb, T.J. (2017). Progressing from 'functional' to mechanistic traits. New Phytol , 215, 9-11.

Chapin, F.S. (1983). Direct and indirect effects of temperature on arctic plants. Polar Biology , 2, 47-52.

Chapin III, F.S., Bret-Harte, M.S., Hobbie, S.E. \& Zhong, H. (1996). Plant functional types as predictors of transient responses of arctic vegetation to global change. Journal of Vegetation Science, 7, 347-358.

Crawley, M.J. (2007). The R book . Wiley, Chichester, England.

Daley, M.J. \& Phillips, N.G. (2006). Interspecific variation in nighttime transpiration and stomatal conductance in a mixed New England deciduous forest. Tree Physiology , 26, 411-419.

Davis, M.B. \& Shaw, R.G. (2001). Range shifts and adaptive responses to quaternary climate change. Science , 292, 673-679.

De Bello, F., Lepš, J. \& Sebastià, M.-T. (2005). Predictive value of plant traits to grazing along a climatic gradient in the Mediterranean. Journal of Applied Ecology , 42, 824-833.

Dray, S., Chessel, D. \& Thioulouse, J. (2003). Co-Inertia analysis and the linking of ecological data tables. Ecology , 84, 3078-3089.

Farquhar, G. \& Wong, S. (1984). An empirical model of stomatal conductance. Functional Plant Biol. , 11, 191-210.

Fridley, J.D., Lynn, J.S., Grime, J.P. \& Askew, A.P. (2016). Longer growing seasons shift grassland vegetation towards more-productive species. Nature Climate Change , 6, 865-868.

Fyllas, N.M., Gloor, E., Mercado, L.M., Sitch, S., Quesada, C.A., Domingues, T.F., et al. (2014). Analysing Amazonian forest productivity using a new individual and trait-based model (TFS v.1).Geosci. Model Dev. , 7, 1251-1269.

Gauslaa, Y. (1984). Heat resistance and energy budget in different Scandinavian plants. Ecography , 7, 5-6.

Gottfried, M., Pauli, H., Futschik, A., Akhalkatsi, M., Barančok, P., Benito Alonso, J.L., et al. (2012). Continent-wide response of mountain vegetation to climate change. Nature Clim Change , 2, 111-115. 
Govaert, S., Vangansbeke, P., Blondeel, H., Steppe, K., Verheyen, K. \& De Frenne, P. (2021). Rapid thermophilization of understorey plant communities in a 9 year-long temperate forest experiment. $J$ Ecol , 1365-2745.13653.

Griffin-Nolan, R.J., Bushey, J.A., Carroll, C.J.W., Challis, A., Chieppa, J., Garbowski, M., et al. (2018). Trait selection and community weighting are key to understanding ecosystem responses to changing precipitation regimes. Funct Ecol, 32, 1746-1756.

Grime, J.P. (2006). Plant strategies, vegetation processes, and ecosystem properties. John Wiley \& Sons.

Harte, J. \& Shaw, R. (1995). Shifting dominance within a montane vegetation community: results of a climate-warming experiment.Science , 267, 876-880.

IPCC. (2021). Climate Change 2021: The Physical Science Basis. Contribution of Working Group I to the Sixth Assessment Report of the Intergovernmental Panel on Climate Change . Cambridge University Press.

Jentsch, A. \& Beierkuhnlein, C. (2008). Research frontiers in climate change: Effects of extreme meteorological events on ecosystems. Comptes Rendus Geoscience, 340, 621-628.

June, T., Evans, J.R. \& Farquhar, G.D. (2004). A simple new equation for the reversible temperature dependence of photosynthetic electron transport: a study on soybean leaf. Functional Plant Biol. , 31, 275.

Kearney, M. \& Porter, W. (2009). Mechanistic niche modelling: combining physiological and spatial data to predict species' ranges. Ecology Letters , 12, 334-350.

Kichenin, E., Wardle, D.A., Peltzer, D.A., Morse, C.W. \& Freschet, G.T. (2013). Contrasting effects of plant inter- and intraspecific variation on community-level trait measures along an environmental gradient.Funct Ecol , 27, 1254-1261.

Koehler, K., Center, A. \& Cavender-Bares, J. (2012). Evidence for a freezing tolerance-growth rate tradeoff in the live oaks (Quercus series Virentes) across the tropical-temperate divide. New Phytologist, 193, $730-744$.

Körner, Ch. \& Diemer, M. (1987). In situ photosynthetic responses to light, temperature and carbon dioxide in herbaceous plants from low and high altitude. Functional Ecology , 1, 179.

Körner, Ch., Farquhar, G.D. \& Roksandic, Z. (1988). A global survey of carbon isotope discrimination in plants from high altitude. Oecologia , 74, 623-632.

Körner, Ch., Farquhar, G.D. \& Wong, S.C. (1991). Carbon isotope discrimination by plants follows latitudinal and altitudinal trends. Oecologia , 88, 30-40.

Lavorel, S. \& Garnier, E. (2002). Predicting changes in community composition and ecosystem functioning from plant traits: revisiting the Holy Grail. Functional Ecology , 16, 545-556.

Liu, D., Ogaya, R., Barbeta, A., Yang, X. \& Peñuelas, J. (2015). Contrasting impacts of continuous moderate drought and episodic severe droughts on the aboveground-biomass increment and litterfall of three coexisting Mediterranean woody species. Global Change Biology , 21, 4196-4209.

Lynn, J.S., Klanderud, K., Telford, R.J., Goldberg, D.E. \& Vandvik, V. (2021). Macroecological context predicts species' responses to climate warming. Glob Change Biol, gcb.15532.

Medeiros, C.D., Scoffoni, C., John, G.P., Bartlett, M.K., Inman-Narahari, F., Ostertag, R., et al. (2019). An extensive suite of functional traits distinguishes Hawaiian wet and dry forests and enables prediction of species vital rates. Funct Ecol, 33, 712-734.

Moreno-Gutierrez, C., Dawson, T.E., Nicolas, E. \& Querejeta, J.I. (2012). Isotopes reveal contrasting water use strategies among coexisting plant species in a Mediterranean ecosystem. New Phytol , 196, 489-496. 
Nakagawa, S. \& Schielzeth, H. (2013). A general and simple method for obtaining $R^{2}$ from generalized linear mixed-effects models. Methods Ecol Evol , 4, 133-142.

Paine, C.E.T., Amissah, L., Auge, H., Baraloto, C., Baruffol, M., Bourland, N., et al. (2015). Globally, functional traits are weak predictors of juvenile tree growth, and we do not know why. $J$ Ecol , 103, 978-989.

Parmesan, C. \& Yohe, G. (2003). A globally coherent fingerprint of climate change impacts across natural systems. Nature, $421,37-42$.

Pellissier, L., Descombes, P., Hagen, O., Chalmandrier, L., Glauser, G., Kergunteuil, A., et al. (2018). Growth-competition-herbivore resistance trade-offs and the responses of alpine plant communities to climate change. Funct Ecol, 32, 1693-1703.

Perez-Ramos, I.M., Matias, L., Gomez-Aparicio, L. \& Godoy, O. (2019). Functional traits and phenotypic plasticity modulate species coexistence across contrasting climatic conditions. Nat Commun , 10, 2555.

Perez-Ramos, I.M., Roumet, C., Cruz, P., Blanchard, A., Autran, P. \& Garnier, E. (2012). Evidence for a 'plant community economics spectrum' driven by nutrient and water limitations in a Mediterranean rangeland of southern France. J Ecol , 100, 1315-1327.

van der Plas, F., Schroder-Georgi, T., Weigelt, A., Barry, K., Meyer, S., Alzate, A., et al. (2020). Plant traits alone are poor predictors of ecosystem properties and long-term ecosystem functioning. Nat Ecol Evol

Poorter, H., Niinemets, U., Poorter, L., Wright, I.J. \& Villar, R. (2009). Causes and consequences of variation in leaf mass per area (LMA): a meta-analysis. New Phytologist , 182, 565-588.

R Core Team. (2018). R: A language and environment for statistical computing. R Foundation for Statistical Computing, Vienna, Austria.

Rasband, W.S. (1997). ImageJ . U. S. National Institutes of Health, Bethesda, Maryland, USA.

Ripley, B.S., Edwardes, A., Rossouw, M.W., Smith, V.R. \& Midgley, G.F. (2020). Invasive grasses of subAntarctic Marion Island respond to increasing temperatures at the expense of chilling tolerance.Annals of Botany , 125, 765-773.

Roden, J.S. \& Farquhar, G.D. (2012). A controlled test of the dual-isotope approach for the interpretation of stable carbon and oxygen isotope ratio variation in tree rings. Tree Physiology , 32, 490-503.

Roderick, M.L. \& Berry, S.L. (2001). Linking wood density with tree growth and environment: a theoretical analysis based on the motion of water. New Phytologist , 149, 473-485.

Rosado, B.H.P., Dias, A.T.C. \& Mattos, E.A. de. (2013). Going back to basics: importance of ecophysiology when choosing functional traits for studying communities and ecosystems. NatCon , 11, 15-22.

Saurer, M., Kirdyanov, A.V., Prokushkin, A.S., Rinne, K.T. \& Siegwolf, R.T.W. (2016). The impact of an inverse climate-isotope relationship in soil water on the oxygen-isotope composition of Larix gmelinii in Siberia. New Phytol, 209, 955-964.

Scheidegger, Y., Saurer, M., Bahn, M. \& Siegwolf, R. (2000). Linking stable oxygen and carbon isotopes with stomatal conductance and photosynthetic capacity: a conceptual model. Oecologia , 125, 350-357.

Shipley, B., De Bello, F., Cornelissen, J.H.C., Laliberte, E., Laughlin, D.C. \& Reich, P.B. (2016). Reinforcing loose foundation stones in trait-based plant ecology. Oecologia , 180, 923-931.

Siefert, A., Violle, C., Chalmandrier, L., Albert, C.H., Taudiere, A., Fajardo, A., et al. (2015). A global meta-analysis of the relative extent of intraspecific trait variation in plant communities.Ecology Letters , 18, 1406-1419. 
Smith, M.D., Knapp, A.K. \& Collins, S.L. (2009). A framework for assessing ecosystem dynamics in response to chronic resource alterations induced by global change. Ecology , 90, 3279-3289.

Smith, W.K. \& Donahue, R.A. (1991). Simulated influence of altitude on photosynthetic CO2 uptake potential in plants. Plant Cell Environ, 14, 133-136.

Snyder, K.A. (2003). Night-time conductance in C3 and C4 species: do plants lose water at night? Journal of Experimental Botany , 54, 861-865.

Soudzilovskaia, N.A., Elumeeva, T.G., Onipchenko, V.G., Shidakov, I.I., Salpagarova, F.S., Khubiev, A.B., et al. (2013). Functional traits predict relationship between plant abundance dynamic and long-term climate warming. Proceedings of the National Academy of Sciences , 110, 18180-18184.

Suttle, K.B., Thomsen, M.A. \& Power, M.E. (2007). Species interactions reverse grassland responses to changing climate. Science, 315, 640.

Swenson, N.G., Worthy, S.J., Eubanks, D., Iida, Y., Monks, L., Petprakob, K., et al. (2020). A reframing of trait-demographic rate analyses for ecology and evolutionary biology. International Journal of Plant Sciences , 181, 33-43.

Taiz, L. \& Zeiger, E. (2010). Plant physiology . 5th edn. Sinauer Associates Inc, Sunderland, MA, U.S.A.

Terashima, I., Masuzawa, T., Ohba, H. \& Yokoi, Y. (1995). Is Photosynthesis Suppressed at Higher Elevations Due to Low $\mathrm{CO}_{2}$ Pressure? Ecology , 76, 2663-2668.

Tjoelker, M.G., Oleksyn, J. \& Reich, P.B. (2001). Modelling respiration of vegetation: evidence for a general temperature-dependent Q10.Global Change Biology , 7, 223-230.

Valladares, F., Sanchez-Gomez, D. \& Zavala, M.A. (2006). Quantitative estimation of phenotypic plasticity: bridging the gap between the evolutionary concept and its ecological applications. J Ecology, 94, 1103-1116.

Vandvik, V., Skarpaas, O., Klanderud, K., Telford, R.J., Halbritter, A.H. \& Goldberg, D.E. (2020). Biotic rescaling reveals importance of species interactions for variation in biodiversity responses to climate change. Proc Natl Acad Sci USA, 117, 22858-22865.

Vendramini, F., Diaz, S., Gurvich, D.E., Wilson, P.J., Thompson, K. \& Hodgson, J.G. (2002). Leaf traits as indicators of resource-use strategy in floras with succulent species. New Phytologist , 154, 147-157.

Verheijen, L.M., Brovkin, V., Aerts, R., Bonisch, G., Cornelissen, J.H.C., Kattge, J., et al. (2013). Impacts of trait variation through observed trait-climate relationships on performance of an Earth system model: a conceptual analysis. Biogeosciences , 10, 5497-5515.

Volaire, F., Gleason, S.M. \& Delzon, S. (2020). What do you mean "functional" in ecology? Patterns versus processes. Ecol. Evol. , 10, 11875-11885.

Wang, H., Prentice, I.C., Davis, T.W., Keenan, T.F., Wright, I.J. \& Peng, C. (2017). Photosynthetic responses to altitude: an explanation based on optimality principles. New Phytologist , 213, 976-982.

Weigt, R.B., Braunlich, S., Zimmermann, L., Saurer, M., Grams, T.E.E., Dietrich, H.-P., et al. (2015). Comparison of $\delta^{18} \mathrm{O}$ and $\delta{ }^{13} \mathrm{C}$ values between tree-ring whole wood and cellulose in five species growing under two different site conditions: Comparing $\delta^{18} \mathrm{O}$ and $\delta^{13} \mathrm{C}$ values of tree-ring whole wood and cellulose.Rapid Commun. Mass Spectrom. , 29, 2233-2244.

Werner, R.A. \& Brand, W.A. (2001). Referencing strategies and techniques in stable isotope ratio analysis. Rapid Commun. Mass Spectrom., 15, 501-519.

Werner, R.A., Bruch, B.A. \& Brand, W.A. (1999). ConFlo III - an interface for high precision $\delta 13 \mathrm{C}$ and $\delta 15 \mathrm{~N}$ analysis with an extended dynamic range. Rapid Communications in Mass Spectrometry , 13, 1237-1241.

Westoby, M. (1998). A leaf-height-seed (LHS) plant ecology strategy scheme. Plant and Soil , 199, 213-227. 
Wright, S.J., Kitajima, K., Kraft, N.J.B., Reich, P.B., Wright, I.J., Bunker, D.E., et al. (2010). Functional traits and the growth-mortality trade-off in tropical trees. Ecology , 91, 3664-3674.

Yang, J., Cao, M. \& Swenson, N.G. (2018). Why functional traits do not predict tree demographic rates. Trends in Ecology 83 Evolution, 33, 326-336.

Zhang, B., Hautier, Y., Tan, X., You, C., Cadotte, M.W., Chu, C.,et al. (2020). Species responses to changing precipitation depend on trait plasticity rather than trait means and intraspecific variation. Funct. Ecol. , 1365-2435.13675.

Figure 1. The interaction between warming and trait value, as a) the second axis of the PCA including all traits combined (describing plant size and water use strategy), as b) the second axis of a PCA with morphological traits only (describing plant size) and as c) the second axis of a PCA with ecophysiological traits only (describing water use strategy). Larger trait values correspond to larger size and/or more conservative water use strategy, as indicated by the arrow. Note that the axis in panel c) has been inverted to make the comparison between the panels easier. Lines are model predictions, points are raw data. The y-axes are changes in frequency (i.e. final/initial), in order to visualize the trends while taking into account the differences in initial frequency. The grey dashed line represents a relative frequency of 1 , i.e. separating "losers" (below the line) from "winners" (above the line). For cover changes, see Supporting Information Figure S11a,c,d.

Figure 2. Species position in the trait space based on a) morphological traits only and b) ecophysiological traits only, c-d) indicating the traits governing the trait space. The first morphological axis describes leaf structure, and the second morphological axis describes plant size. The first ecophysiological axis describes plant gas exchange and the second ecophysiological axis describes integrated water use strategy. For both PCAs, the second axis correlates with species' cover and frequency change to warming. In addition, the first morphological axis correlates with species cover change. Species are colored according to their position on the second axis, because for both PCAs, the second axis correlates with species' cover and frequency change to warming; red colors indicate species less vulnerable to warming according to that trait axis. For the PCA including all traits combined, see Supporting Information Figure S10.

Figure 3. Community-weighted means for $\delta^{18} \mathrm{O}$ (correlating negatively with life-time stomatal conductance) and $\delta^{13} \mathrm{C}$ (correlating positively with life-time water use efficiency). Panels a) and c) show changes in community mean values when only changes in species frequency are taken into account (i.e. mean species trait values measured at $+0^{\circ} \mathrm{C}$ ). Panels b) and d) show changes in community-weighted values when both changes in species frequency and intra-specific trait changes are taken into account (i.e. site-specific trait values). See Supporting Information Figures S5-S6 for intra-specific changes in traits due to warming. The overall community-level effect of the transplantation was significantly higher life-time stomatal conductance $\left(\mathrm{GS}\right.$; lower $\delta^{18} \mathrm{O} ; \mathrm{F}(1,48)=90.93, \mathrm{p}<0.001$, panel b) and lower life-time water use efficiency (WUE; $\delta^{13} \mathrm{C}$; $\mathrm{F}(1,48)=8.75, \mathrm{p}=0.005 \mathrm{~m}$ panel $\mathrm{d})$ at the warmest site $\left(1000 \mathrm{~m},+5^{\circ} \mathrm{C}\right)$.

Figure 4. Relationship between species' vulnerability to climate change based on morphological or ecophysiological traits only. Panel a) shows species ranked from most vulnerable to warming (1) to least vulnerable (16), according to their position on the second trait axis of the PCA with morphological or ecophysiological traits only (i.e. describing either size or water use strategy). The dashed line indicates 1:1 relationship, i.e. the further the species falls from the line, the more different are the two rankings for that species. Panel b) shows the correlation with the trait axes themselves.

Table 1. Information on the study sites along the elevational gradient. The experiment was located in the eastern Swiss Alps (Calanda mountain, 46 $88^{\prime} \mathrm{N}, 9^{\circ} 49^{\prime} \mathrm{E}, 2805 \mathrm{~m}$ ). The meteorological values are means over the summers 2019-20. Errors are standard deviations. See also Supporting Information Figure S1.

\begin{tabular}{llll}
\hline Warming based on elevation & Elevation & Summer temperature & Soil moisture \\
\hline$+0^{\circ} \mathrm{C}$ & $2000 \mathrm{~m}$ & $10.7^{\circ} \mathrm{C} \pm 5.4^{\circ} \mathrm{C}$ & $34.3 \% \pm 9.6 \%$
\end{tabular}




\begin{tabular}{llll}
\hline Warming based on elevation & Elevation & Summer temperature & Soil moisture \\
\hline$+2^{\circ} \mathrm{C}$ & $1600 \mathrm{~m}$ & $12.5^{\circ} \mathrm{C} \pm 6.0^{\circ} \mathrm{C}$ & $25.3 \% \pm 10.4 \%$ \\
$+3^{\circ} \mathrm{C}$ & $1400 \mathrm{~m}$ & $13.2^{\circ} \mathrm{C} \pm 6.1^{\circ} \mathrm{C}$ & $25.7 \% \pm 11.0 \%$ \\
$+5^{\circ} \mathrm{C}$ & $1000 \mathrm{~m}$ & $15.6^{\circ} \mathrm{C} \pm 5.8^{\circ} \mathrm{C}$ & $22.6 \% \pm 11.8 \%$ \\
\hline
\end{tabular}

Table 2. Summary of the traits measured. "Sites" -column lists at which sites the trait was measured.

\begin{tabular}{|c|c|c|}
\hline Acronym & Explanation & Unit \\
\hline A & Photosynthetic rate at $1000 \mu \mathrm{mol} \mathrm{m}{ }^{-2} \mathrm{~s}^{-1} \mathrm{PAR}$ & $\mu \mathrm{mol} \mathrm{CO}_{2} \mathrm{~m}^{-2} \mathrm{~s}^{-1}$ \\
\hline $\mathrm{R}$ & Night respiration rate & $\mu \mathrm{mol} \mathrm{CO}_{2} \mathrm{~m}^{-2} \mathrm{~s}^{-1}$ \\
\hline GS & Stomatal conductance during the day & $\mathrm{mmol} \mathrm{CO}_{2} \mathrm{~m}^{-2} \mathrm{~s}^{-1}$ \\
\hline $\mathrm{E}$ & Transpiration durign the day & $\mathrm{mmol} \mathrm{H}_{2} \mathrm{O} \mathrm{m}^{-} 2 \mathrm{~s}^{-1}$ \\
\hline WUE $_{\text {int }}$ & Intrinsic water use efficiency, A/GS & \\
\hline WUE $_{\text {inst }}$ & Instantenious water use efficiency, $\mathrm{A} / \mathrm{E}$ & Instantenious water use efficiency, $\mathrm{A} / \mathrm{E}$ \\
\hline $\mathrm{GS}_{\text {night }}$ & Stomatal conductance during the night & $\mathrm{mmol} \mathrm{CO} \mathrm{Cm}^{-2} \mathrm{~s}^{-1}$ \\
\hline$E_{\text {night }}$ & Transpiration durign the night & $\mathrm{mmol} \mathrm{H}_{2} \mathrm{O} \mathrm{m} \mathrm{m}^{-2} \mathrm{~s}^{-1}$ \\
\hline $\mathrm{T}_{\text {opt }}$ & Optimal tenperaure for photosynthesis & ${ }^{\circ} \mathrm{C}$ \\
\hline$\Omega$ & The temperature range when photosynthesis is above zero & ${ }^{\circ} \mathrm{C}$ \\
\hline $\mathrm{Q}_{10}$ & The increase in respiration rate as temperature increases $10^{\circ} \mathrm{C}$ & $\mu \mathrm{mol} \mathrm{CO}_{2} \mathrm{~m}^{-2} \mathrm{~s}^{-1}$ \\
\hline LMA & Leaf mass per area & $\mathrm{mg} / \mathrm{mm}^{2}$ \\
\hline LA & Leaf area & $\mathrm{cm}^{2}$ \\
\hline LT & Leaf (lamina) thickness & $\mathrm{mm}$ \\
\hline LDMC & Leaf dry matter content & $\%$ \\
\hline $\mathrm{C}$ & Leaf carbon content & $\%$ \\
\hline $\mathrm{N}$ & Leaf nitrogen content & $\%$ \\
\hline $\mathrm{C}: \mathrm{N}$ & Leaf carbon to nitrogen ratio & \\
\hline PNUE & Photosynthetic nitrogen use efficiency & $\mu \mathrm{mol} \mathrm{CO}_{2} \mathrm{~g}^{-1} \mathrm{~s}^{-1}$ \\
\hline height & Height of plants without including reproductive parts & $\mathrm{mm}$ \\
\hline width & Horizontal width of the aboveground plant & $\mathrm{mm}$ \\
\hline $\operatorname{Root}_{d}$ & The depth of the root system & $\mathrm{mm}$ \\
\hline $\operatorname{Root}_{\mathrm{w}}$ & Maximum horizontal distance of a root from the rooting point & $\mathrm{mm}$ \\
\hline CSI & Canopy shape index: lateral spread of the canopy / height & ranges from values close to 0 for erect plants \\
\hline$\delta^{13} \mathrm{C}$ & Carbon isotope ratio of leaf celluloce & All sites \\
\hline$\delta^{18} \mathrm{O}$ & Oxygen isotope ratio of leaf celluloce & All sites \\
\hline$\delta^{18} \mathrm{O}_{\text {enrich }}$ & $\mathrm{d}^{18} \mathrm{O}$ enrichment over the source water & depth \\
\hline $\mathrm{cm}$ & All sites & \\
\hline PI & Plasticity index of the corresponding trait & ranges from values 0 (no plasticity) to 1 , or \\
\hline
\end{tabular}


a)

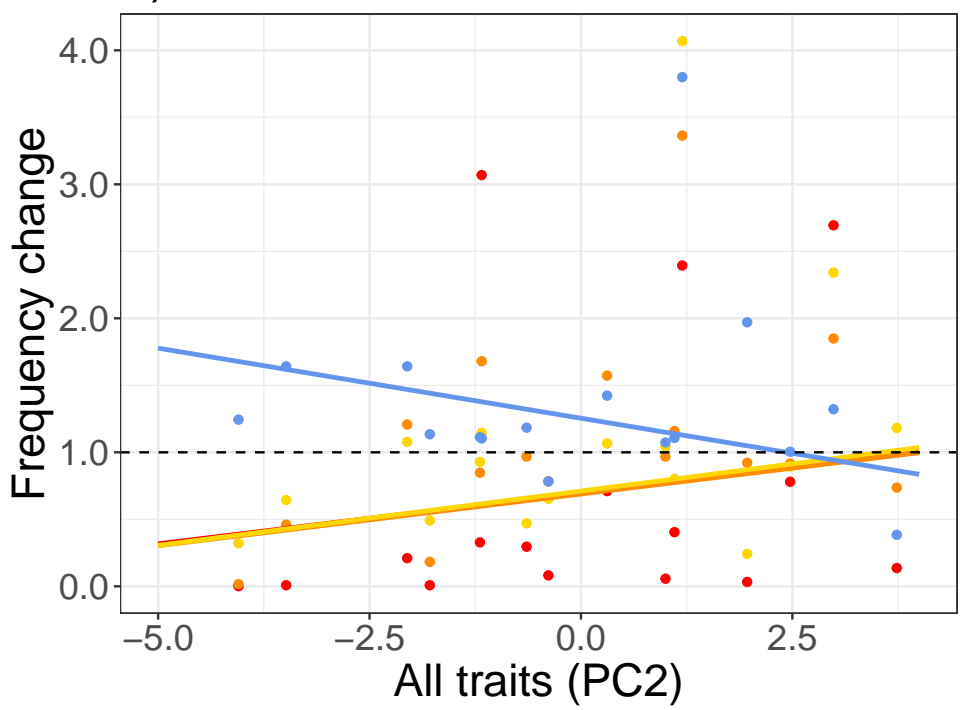

b)

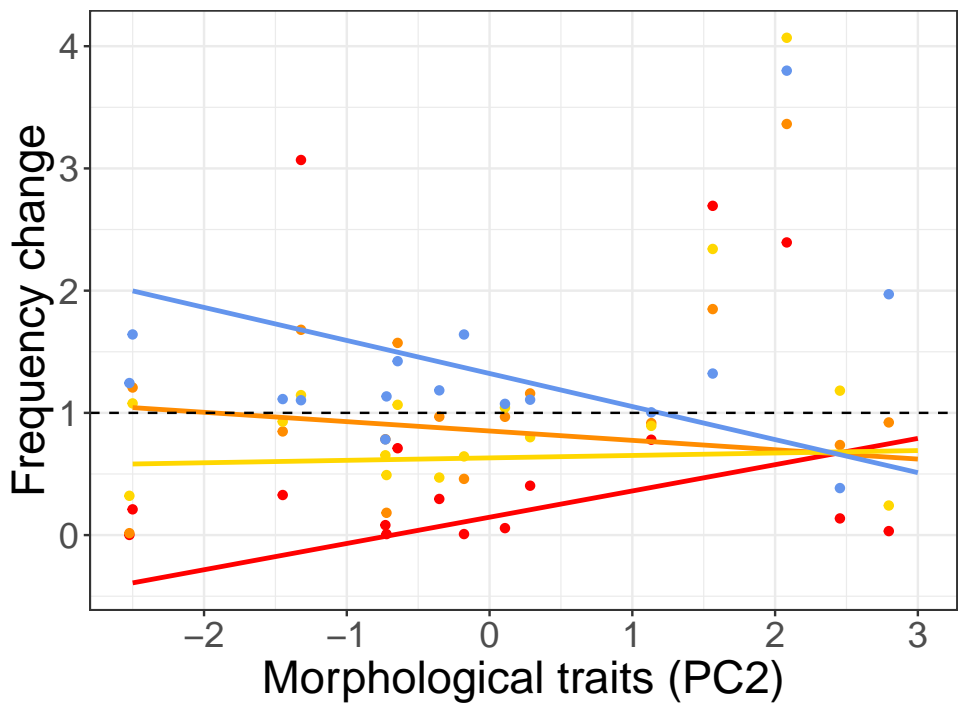

c)

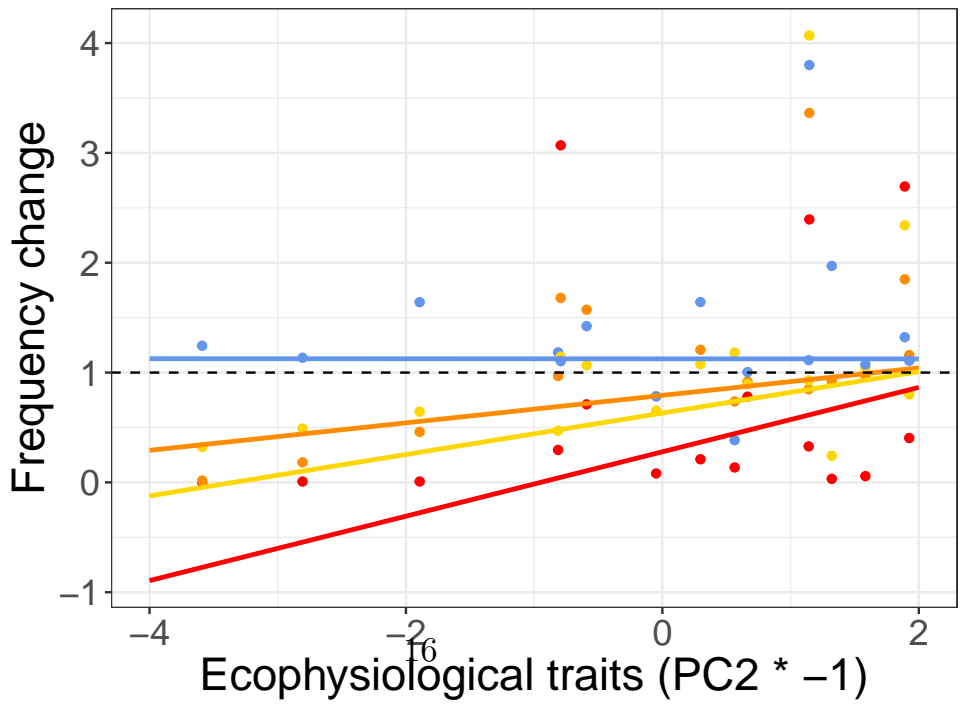

Larger size and/or more conservative water use 

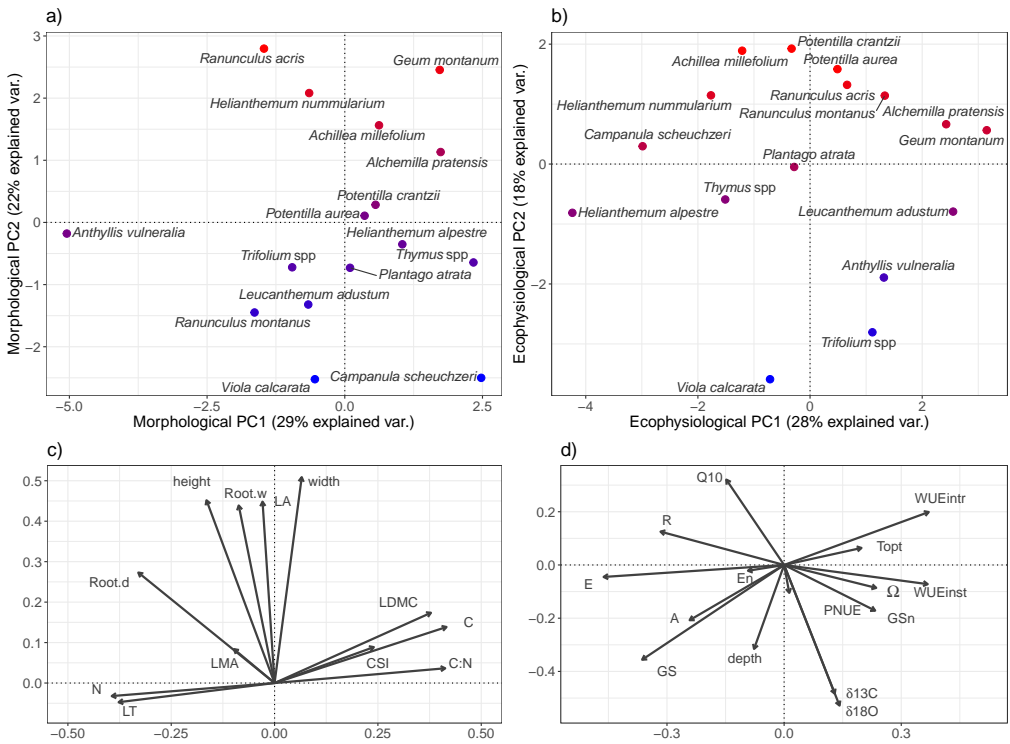

a) Species freq. change

b) Plasticity + species freq. change
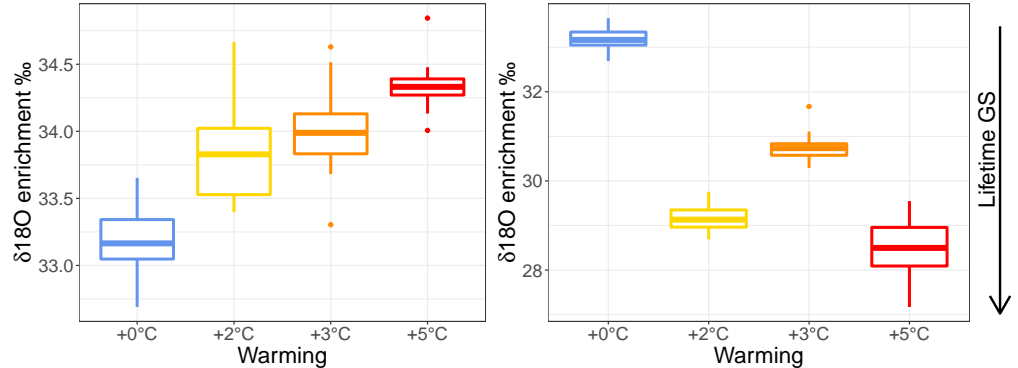

c) Species freq. change

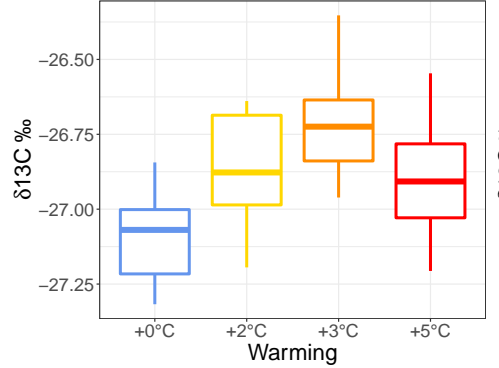

d) Plasticity + species freq. change

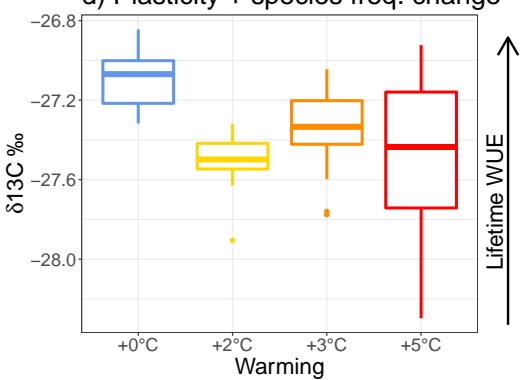


a)

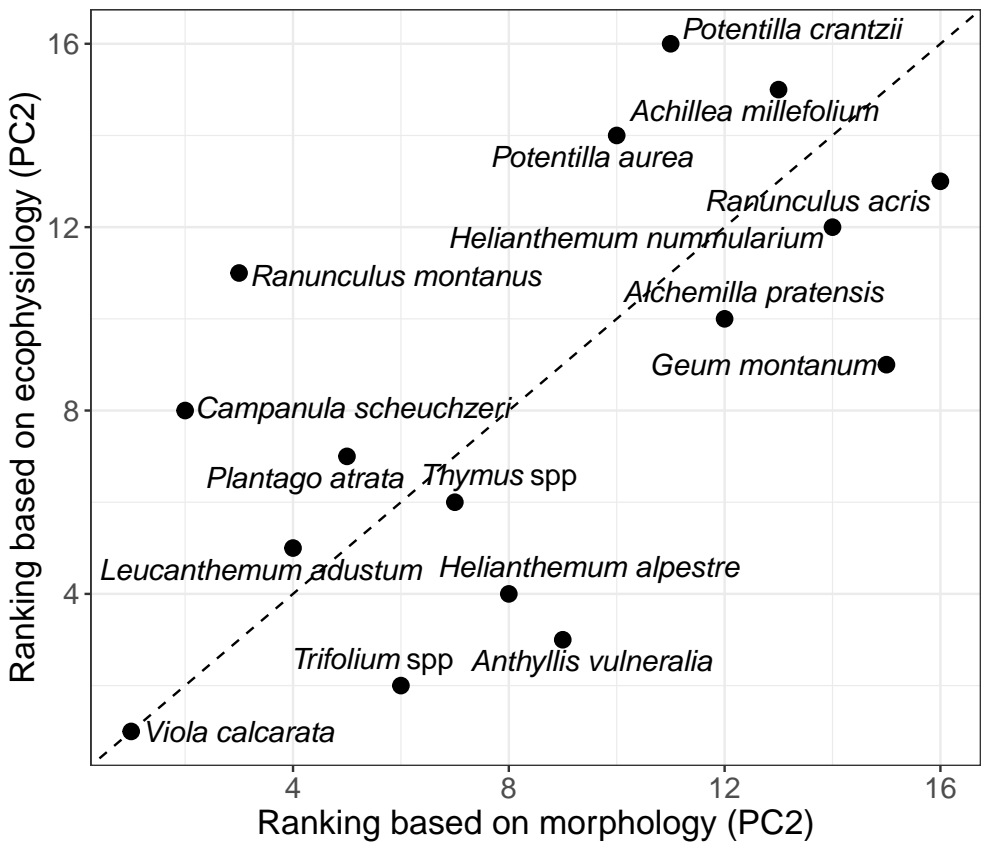

b)

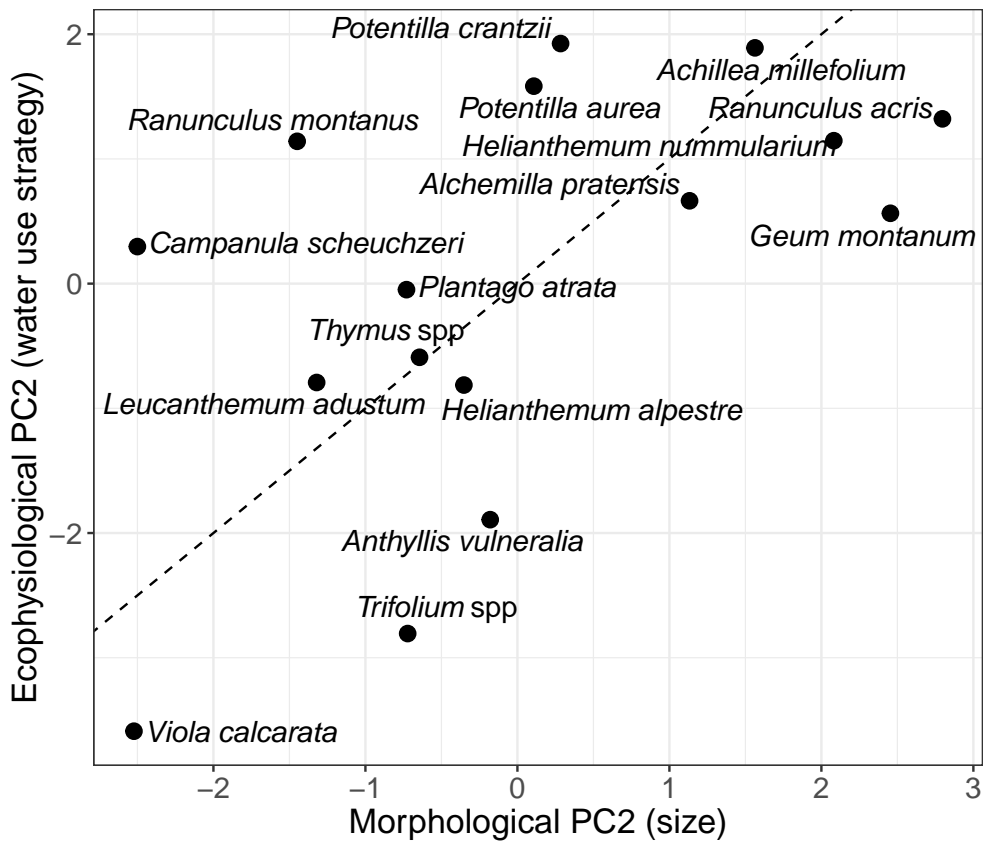

